\title{
Be a Sedentary Confucian Gentlemen: The Construction of Anti-Physical Culture by Chinese Dynasts Using Confucianism and the Civil Service Examination
}

\author{
Junwei $\mathrm{Yu}$
}

National Taiwan College of Physical Education, Taiwan

ABSTRACT

\begin{abstract}
Although there has been a growing body of research that explores Chinese masculinities within imperial China, the connection between masculinity and physical culture has been neglected. In this article, the author argues that Chinese emperors used Confucianism and the civil service examination (keju) to rule the country, and at the same time, created a social group of sedentary gentlemen whose studiousness and bookishness were worshiped by the public. In particular, the political institution of $k e j u$ played a crucial role in disciplining the body. Behavior that did not conform to the Confucian standards which stressed civility and education were considered barbaric. As a result, a wen-version of masculinity was constructed. In other words, an antiphysical culture that strengthened the gross contempt towards those who chose to engage in physical labor.

China, confucianism, gentleman, physical culture, civil service examination
\end{abstract}

Current Western ideals of how men should behave have dominated the standard setting discourse against which other forms of masculinity are measured and evaluated. Set against the 'macho' stereotype circulating in the West, images of Chinese men do not conform to this type of masculinity, and the same associations of manliness do not exist. Yet pre-modern Chinese have nonetheless sought to define the normative ideal of male behavior, as this article will demonstrate. Therefore, masculinity is never a monolithic concept. Indeed, the meaning of masculinity is neither transhistorical nor culturally universal, and should take into account non-western possibilities, in this case, Confucianism and the tailor-made civil service examination $(k e j u)$.

The article is divided into four main sections. Firstly, the literature concerning Chinese masculinity in imperial China will be reviewed, followed by the author's argument concerning the $w e n-w u$ paradigm, in which the gentlemen is seen as the ideal model, to which every Chinese male should aspire. Secondly, the way in which successive Chinese dynasts used Confucianism and the $k e j u$, underpinned by Confucian philosophy, to rule a massive empire will be outlined. Thirdly, it will be seen that as a result of dynasts' statecraft, the new class of sedentary gentlemen emerged becoming the guardians, promoters, and models for Chinese society. Finally, pre-modern China will be seen as 
constructing a wen-version of masculinity that absolutely despised physical labor, whilst choosing to adore pure intellectualism.

\section{Gentleman, masculinity, and physical culture}

Several scholars have offered their opinions on Chinese masculinity during pre-modern China. Louie (2002), for instance, has suggested that Chinese masculinity may be theorized as comprising both wen and $w u$, so that a scholar is considered as masculine and as a warrior. Therefore, he was considered to be acceptably manly. It was perceived that in order for the ideal person to pursue successful management of the long-term national and self, a balance should be achieved between the two styles of masculinity. The two forces were portrayed as complementary forces for those men who wanted to achieve good government and personal governance. However, he admits that the relationship between wen and $w u$ does not always enjoy a state of equilibrium, because the former was often prioritized over the latter.

Song (2004) has stated that Chinese masculinity is power based, rather than sex based, as distinct from Western gender construction. He argues that masculinity in pre-modern China has been constructed within a homosocial context, where the yin/yang paradigm was involved. The fragile scholar was dubbed as describing the "emasculation" of the shi class (scholar-officials), whose mainstream masculinity spanned the pre-Qin to Ming and Qing dynasties. However, they belonged to the yin category in relation to the dynasts, just as the wife was in opposition to the husband. In other words, masculinity was built on "a political position within the power system" rather than on biological sex.

Birdwhistell (2007) considers that instead of yinyang thinking, binary cultural categories, such as inner and outer (neiwai) were the criteria of masculinity. This trend was reinforced by specific structural features of society, one of which was the flourishing of the examination system which helped strengthen certain social values. As such, Birdwhistell introduced the civil service examination (keju) into the equation, arguing that people who passed the examination were thought to be outer (wai) associated with a male institution, while those who failed the exams and were not in the government were considered as inner (nei), and connected to female attributes. As keju based on Confucianism developed, especially from the Song period on, these failed men, as well as women, became increasingly restrictive.

All of them had the merits of explaining and interpreting masculinity from different angles, but they rarely touched upon the issue of physical culture, which had been suppressed during imperial China. The author argues that the Chinese constructed a unique wen-version of masculinity; that is, an anti-physical culture, which was in sharp contradiction to the Western world's muscular Christianity, or Japan's samurai spirit, resorting to physical fitness with an ideal of vigorous masculinity. Muscular Christianity refers to a movement that had originated from the Victorian era, and was inspired by Charles Kingsley and Thomas Hughes, who felt that sports and athleticism would produce Christians who were more fit for civic duty. The adventure-seeking male sought fulfillment on the frontiers of the British Empire, based on the gentlemen-amateur ethos found in public schools (Mangan 1998, Money 1997, Rains 2001, Holt 1989, pp. 74-117) or flight from domesticity, as opposed to the warmth of the family hearth (Marshall 2009). By the 1880s, American Protestant churches also endorsed the movement and promoted the culture of physical vigor (Putney 2001).

In contrast, it may be argued that China's cultural tradition consciously distinguished wen and $w u$, meaning the 'civil' (or cultural attainment) and the 'martial' (or physical valor), respectively. However, both 'wen' and 'wu' encompass a broad spectrum of meanings, which are hard to translate succinctly into English. According to the Mandarin Chinese Mini Dictionary (July 5, 2009), wen and $w u$ have ten and three meanings, respectively. Wen denotes 'literary virtue', 'literary talent', 'literary knowledge', 'civil affairs', 'literary way', and 'learning'. It also connotes benevolence, filial piety, respect, loyalty, and learnedness. Meanwhile, wu denotes 'martial arts', 'martial merit', 'military 
strategy', and 'military affairs'. Its connotations include bravery and ferocity, as well as righteousness. Overall, wen refers to the use of mind, while $w u$ concentrates on the body, requiring physical strength. As a consequence, the Chinese wen-wu paradigm serves to prompt a further analysis of masculinity in terms of the distinction between mental and physical.

It is important to pinpoint the educational thinking of Confucianism, which centers mainly on the fostering of junzi, a concept that can be translated as gentleman or exemplary person. Most Chinese men have aspired to be the Confucian ideal of a gentleman over the last two millennia. The word junzi appears in the Analects 106 times. (Zhao 1976, p. 100) In the Analects, wu is closely related to the construction of a gentleman, and the relationship is reiterated several times. However, gentlemen are often not associated with the $w u$ aspect of masculinity. For example, in verse 27, book VI of the Analects, Confucius says 'the junzi is widely versed in wen', which showed the intimate relationship between the two (Confucius 2009, p. 77). Again, in verse 18, Confucius said that 'when there is more $z h i$ [innate nature] than wen, the results will be churlishness. When there is more wen than $z h i$, the result will be pedantry. Only a well-balanced admixture of the two will result in junzi (Confucius 2009, p. 74). In other words, a genteel gentleman may only be achieved through the process of education and enculturation using wen.

Confucius and Mencius both outlined the ideological foundations of the civil-marital divide that heavily influenced the Chinese people. As Confucius stated, "A Gentleman sets his heart on virtue, a petty man sets his heart on land" (junzi huaide xiaoren huaitu), implying the so-called gentlemen should not get involved in physical work, such as farming. (Confucius 1960, p. 47) Mencius further developed this idea by commenting as follows:

Great men (gentlemen) have their proper business, and little men (petty men) have their proper business... Hence there is the saying 'some labor with their minds and some labor with their strength. Those who labor with their minds govern others; those who labor with their strength are governed by others. Those who are governed by others support them; those who govern others are supported by them.' (Laoxin zhe zhiren, laoli zhe zhiyuren.) This is a principle universally recognized. (Mencius 1960, p. 124)

Given such a rationale, the ancient Chinese developed the concept of "the distinction between hua and yi" (huayi zhibian), which sharply distinguished a wen-defined "China" (called hua) from cultural or ethnic outsiders (often called barbarians) to deal with the nomads, who were more warlike and muscular, yet undereducated and ill-mannered, and therefore matched the wu aspect. Since Confucianism is the mainstream culture within Chinese societies, it is unsurprising that Confucian tenants were used as a yardstick for judging barbarity (the other) and civilization (the self). By portraying other peoples as barbarous, the Chinese evidently included civilization as an integral part of their own national identity (Terrill 2003, p. 41). In forging mental associations between non-Chinese and animals, the Chinese ruling class could situate Confucianism on a higher cultural plane, under which lesser people could be salvaged (Dikotter 1992, pp. 8-9, Crossley 1999, pp. 281-295).

\section{Confucianism and $k e j u$ as a means of statecraft}

\section{Confucian paternalism}

Confucianism is an ethical and moral philosophy based on the teachings of Confucius (551-479 B.C.), who lived in a turbulent period in China's history. At the time of his birth, the Eastern Zhou Dynasty (770-256 B.C.) was in decline, and many of the social, ethical and spiritual values were being subjected to re-examination. Feudal warlords asserted their own supremacy, and ministers with different clan affiliations acted in accordance with whatever advantages they could garner in their own interests. Throughout his life, Confucius traveled extensively, teaching about social and ethical reform. However, he never achieved recognition or reward in his own lifetime. 
It was only with the Han Dynasty (206-221 A.D.) that his teachings would be fully embraced within China's political and social system, while all other schools of thought were banned following the proposition of the Confucian scholar Dong Zhongshu (179-104 B.C.). Henceforth, Confucianism was to be the dominant orthodox ideology of China until the Xinhai Revolution (1911) ${ }^{1}$. State education, according to Confucianism, was created by the Han Period's emperor Wudi in 124 B.C. Provincial schools were established, and the Confucian tradition of education spread across China. The texts systematically adopted within official guidelines are known as the Five Classics (wujing) and the Four Books $(s i s h u)^{2}$. From then on, the Confucian hegemony was firmly established, since the following dynasties, largely out of convenience, made Confucianism their official ideology. This was further reinforced through the machinery of imperial civil service examinations.

The Confucian ideology, which has dominated for more than two millennia, has played a major role in China's state-society relations, in which $l i$ governs every aspect of interpersonal relations, including government (Zhao 1996, pp. 1-41, Li 1999, pp. 173-197). Li encompasses a wide range of meanings, including ritualized conduct of all types, from routine daily greetings to major ceremonies. It can mean written and unwritten social and behavioral norms. Some people translate $l i$ as rites, rituals and rules of conduct, and so on. It regulates harmonious relations between people, promotes one's education and ethics, and maintains social order. Imperialists and philosophers constructed a moral and universal relation around Confucian's concept of five fundamental ethical relationships (wulun): affectionate responsibility between father and son; righteous loyalty between monarch and minister; attention to appropriate roles for husbands and wives; proper hierarchy between elder and younger; and faithfulness between friends. In other words, the latter needed to be subservient to the former. Rulers, fathers or the local elite led by upright example, by maintaining proper relations of hierarchy. (Kang 1993, p. 39) The best way to describe Confucian government is probably 'paternalism, in which the ruler makes decisions for the subjects' benefit and instructs them how to live their lives'. Peace and tranquility are thus maintained if everyone adheres to his or her position according to the proper relations mentioned by Confucius.

It is universally agreed that the family is central to Confucianism, and filial piety, such as having an absolute obedience toward parents and, by extension, to ancestors, remains the most important moral value. This kind of individual conformity was reinforced by the gruesome civil service examination $(k e j u)$, for which wholehearted support was frequently offered in great anticipation by the family. The thinking of Confucianism and, most important of all, the civil service examinations have had a profound impact on Chinese notions of academic study and physical exercise.

\section{Fallen into emperor's trap}

"The heroes of the empire are all fallen into my trap" was a famous remark made by Emperor Tang Taizong (599-649 A.D.). After observing the splendid sight of those who passed the civil service examination, leaving the government building in a triumphant column (Guo 1994, p. 63). In 605 A.D., Emperor Sui Yangdi (569-618 A.D.) formally established the first Chinese keju, which lasted until 1905 , and the repercussions have lingered to the present day. The keju, with its 1,300-year history, was the most important means of recruiting state officials within the Chinese imperial state. It was devised as a centralist strategy by the dynasts of a newly reunified empire to gain political control of an imperial government, which has been historically dominated by guizu (aristocrats) (Fu 1994, pp. 219222).

\footnotetext{
${ }^{1}$ According to Tu Wei-ming, Confucianism is known to have three stages: Han Confucianism, Song-Ming NewConfucianism, and New Confucianism. (Bresciani, 2001, 11-31).

2 'Four Books' are the Analects (Lunyu), Mengzi (Mencius), Great Learning (Daxue), and Doctrine of the Mean (Zhongyong). 'Five Classics' refers to the Books of Changes (Yujing), Book of Poetry (Shijing), Book of History (Shujing), Records of Rites (Liji), and Spring and Autumn Annals (Zuozhuan).
} 
For centuries, new dynasties used violent means to overthrow old regimes. Once in control, these emperors soon realized that the actual governance of China would require the administrative services of thousands of bureaucrats. Any founding ruler of a dynasty would be faced with problems in governing the country, such as the lack of capable officials and the fear of military governors in charge of distant provinces leading to frontier revolts against the emperor. This encouraged rulers to use $k e j u$ to equip themselves with governmental personnel that would be loyal to them. As a result, Confucian ethics were a useful instrument of mind control, designed to instill loyalty to the Emperor from inherently antagonistic aristocrats who had historically dominated the imperial government. The system cultivated non-hereditary officials, based on literati merits that bound them with unquestioning loyalty to the ruling class. Keju was never designed to be a liberal reformist mechanism for introducing new ideas, let alone criticism of the government. The incentive for being a state official was so strong that the masses were willing to devote money and time to studying. At the same time, people were tied up in manpower and capital because of the examination, and so would invest less energy in business or politics. The unflagging studies of Confucian Classics could also divert their thoughts and activities from rebellion. The situation may best be summarized by a Chinese proverb: "Scholars stage a rebellion without result even if they try for three years" (xiucai zaofan sannian bucheng) (Wang 2002, pp. 307-348).

From the Ming dynasty onwards, the contents of keju were tested virtually on "the Four Books", namely the great Learning, the Doctrine of the Mean, the Analects of Confucius and Mencius and the Five Classics, namely, the Book of Songs, the Book of History, the Book of Changes, the Book of Rites and the Spring and Autumn Annuals. All candidates had to write a composition, explaining ideas from these books in a rigid form and structure known as the Eight Part Essay (baguwen), introduced in the fourteenth century. The ideas were required to tally with the ideas from the Four Books and the Five Classics. Any innovative or eccentric idea was rejected. Although the system only allowed a tiny amount of participants to enter officialdom, it did cultivate intellectual element within the masses that in turn advanced cultural and social progress within ancient China.

In the end, the contents of the examination became so dull that it served to restrict the thoughts of intellectuals. Gu Yanwu, a famous scholar, declared the Eight Part Essay practice as "more disastrous than "book burning" (the purge of Qin Shihuang, first emperor of the Qin Dynasty, as Confucian books were burnt and Confucian scholars buried alive) (Gu 1976, pp. 476-477).

\section{Sedentary gentlemen on the rise}

\section{The selection process}

The civil service examination system may be seen as a fair test in a man's world that was open to all men of letters, was not for women, and carried no restrictions as regards age or family background. It is true that some men were not allowed to take part because they themselves or their fathers or grandfathers were involved in "basic occupations", such as entertainers, slaves, or government servants, but that percentage was minuscule. The civil service examination, therefore, offered an impartial route to social mobility for everyday citizens. In this way, talents were found and selected by the emperors as a means of serving the feudal government.

The ancient Chinese civil service examination (keju) has been lauded as the finest in its time by setting up an impartial system to select the literati class. However, China's examination system was available to the masses only from the Song dynasty onwards: prior to that, the Sui and Tang dynasties had used it for recruiting civil officials only on a very small scale. Starting from the Song dynasty, social mobility was the major consequence of the examinations. Even the humblest could become a member of the ruling class by passing keju through a Confucian education. Power and wealth supposedly made no difference, and only the level of education as measured by the examinations mattered. 
There were generally three levels of exam - one each at the local, provincial and national levels. District exams held in the county capitals included testing the candidate on his knowledge of the classics, his ability to compose essays on given subjects using set poetic forms, and calligraphy. There was no age limit for the exams. Therefore it was not uncommon to see a twelve-year-old sitting sideby-side with a sixty-year-old man, who, having failed, took the test year after year. (It was difficult to pass even at the district level)

One would be given the name shengyuan, which means 'state student', if one passed the district exams. Successful candidates were also called xiucai, which was the minimal qualification for examiners. At the provincial level, all the xiucans were tested on the breadth of their studies in the Confucian Classics, and these examinations often lasted up to seventy-two hours. Those who passed the provincial level exams were termed juren, which means 'recommended man'. These jurens were not only eligible for the national level exams, but also qualified for an official position in civil administration, even if they failed the national exams. At the national level exams, which were split into two stages, candidates were examined on the ability to analyze contemporary political problems in addition to the usual examinations based on the Confucian classics. Candidates who passed the first stage could enter the highly prestigious special exams held by imperial decree, which offered the top three candidates the title of jinshi or 'presented scholar'.

The success rates of these exams were extremely small. During the Tang dynasty, the pass rate was about two per cent. Furthermore, the process eliminated vast numbers of candidates later in the Ming and Qing dynasty. It was estimated that the odds of passing all the stages of keju might have been "slightly better than the 1 in 6,000 (0.01\%)" (Elman 2000, p. 141). However, the meritocratic nature of these exams has been noted in Chinese history. During the Ming Dynasty, about $42.9 \%$ of those who passed the highest levels of examinations were from families with no official connections (Liu 1992, p. 444, Zhao 1995, p. 296).

\section{The rise of the literati-scholar class}

In contrast to Western education, particularly in regards to the model of higher education in medieval and Renaissance universities where students were encouraged to engage in disputation, traditional Chinese education consisted primarily of rote learning and memorization of the Confucian Classics. The method had become standardized by the seventh century civil service examinations. The purpose was to create a literati-scholar class that accepted an ethical outlook and body of knowledge, but did not seek to expand knowledge or academic specialization (Merson 1990, p. 86). For those who rose through the ranks by passing these exams and were selected for administrative positions, their clans or families also soared in social prestige and wealth.

The acquisition of a Confucian education, and the taking of examinations, became a certification of social status. Scholar status was a social necessity, similar to college graduation in today's context. "The internationalization of a literary culture that was in part defined by the civil examination curriculum influenced the literatus' public and private definition of his moral character and social conscience. A view of government, society, and the individual's role as an elite servant of the dynasty was continually reinforced in the memorization process leading up to the examinations themselves" (Elman 2000, p. 419).

One may imagine a central government with a budget to hire a small administrative staff to run a massive country. The gap between county magistrates sent by the dynasty and the masses was filled with a special group of literati-scholar. The typical member of this class passed the first or second exam, which was usually not enough to become government officials, but was enough to confer local prestige and important benefits, such as exemption from taxes. Although they were not government officials, they were important people who assisted county magistrates by performing certain government functions, such as tax collection, mediation of minor disputes, or punishment of minor 
criminals. Either county magistrates or their assistants were regarded as sedentary gentlemen setting up exemplary model to local areas (Wang 2007, pp. 242-279).

The literati-scholar class (shi) was the highest social group in China, followed by farmers, laborers, and merchants. It was imperative for the dynasts to conform to classical ideals and uphold Confucian orthodoxy, ensuring the officials they chose in the examination would serve the people in the name of the ruling family and become political servants for both the masses and the ruler. In addition, emperors realized that they could enhance their own power by selecting officials regardless of their past background. Therefore, these officials would owe their positions not to any aristocratic status as such, but to the emperor who appointed them. The literati-scholar class, who were deeply influenced by Confucian thought, never formed an independent and autonomous political group against the emperors. Although literati and gentries created academies and schools that could shape popular opinion, similar to Western salons or coffeehouses, their primary function was to provide students with Confucian training in order to take the civil service examinations. This provided "a variety of mediating cultural institutions" for the dynamic interaction between family and state (Jin 1991, p. 30, Tu 1999, pp. 1-29). Therefore, they actively engaged in establishing and imposing normative standards for individuals and communities and control of the state for virtuous ends.

\section{Wen-over-wu mentality and repercussion}

The use of Confucianism, accompanied by keju, contributed to the asymmetrical balance of wen and $w u$. The culture of academic study flourished in the country, throughout which academies and schools were established to teach Confucian thought after Confucianism had been made state ideology during the Han dynasty. The hegemony of the Sui Dynasty was further confirmed by the creation under of the civil service examinations system which focused on Confucian Classics. This produced a 'sedentarizing process' that occurred virtually in every dynasty, and a social impact that exalted sedentary scholars, while at the same time remaining in contempt of physical exercise and manual labor.

\section{'Sedentarizing process'}

The demarcation of wen and $w u$ was finally forged in 702 A.D. when the first and only Chinese Empress, Wu Zetian (624-705 A.D.) created the martial service examination (wuju). At that point, the practice of wen and $w u$ was separated, which had serious and profound implications for the public view of physical strength. The public stereotyped the physical laborers with the label 'shallow mind, strong body' (tounao jiandan sizhi fada), an ancient Chinese proverb. Its status is similar to that of the martial service examination (wuju) in ancient China. Though wuju co-existed with keju, it was not valued by ordinary people, because participants were rarely educated, and cheated in exams. (Liu 1977, pp. 37-38, Zhao 1993, p. 279)

Unlike British and Japanese societies led by public school elites and samurais respectively, stressing the need of physical fitness, Chinese culture was led by a 'Confucian class', possessing entirely intellectual abilities through the keju system. In this regard, physical labor was completely despised. As J.R. Hale commented, "A good soldier is the product of his whole environment, not just a military academy" (Hale 1983, p. 361). British public school alumni and Japanese samurais have been role models in their respective countries. On the contrary, it is the lettered class in Chinese civilization, which is ranked at the very top of the social fabric, fostering a civil-over-martial mentality. Confucian bureaucrats, who constituted less than $0.5 \%$ of the entire population from the Han Dynasty onwards, had ruled the massive territory of China on behalf of their emperors. They were seen as elites, guardians and promoters of Confucianism, safeguarding dynasts' interests as well as their own (Jin and Liu 1994, p. 51). Accordingly, different conceptions of manhood and masculinity can emerge under different historical and ideological contexts. 
The author has coined the term 'sedentarizing process' to explain the general pattern of sinification and keju once adopted by emperors. The idea is adapted from Elias and Dunning's 'civilizing process', in which aggressiveness and cruelty were transformed into mimetic activities, such as sport, since the state monopolized violence and taxation. They rightly pointed out that only Western countries underwent this kind of process, and it could not be applied to other regions (Elias and Dunning 1986). Due to its different culture, China experienced another process.

Different views of physical labor and warlike spirit regarding the use of the body can be discerned among the northern nomads who adopted Confucianism after they entered northern and central China. The Khitan race established the Liao Dynasty (907-1125 A.D.) and concomitantly set up a keju system exclusively for the Han Chinese, as the ruling class feared their people's combat capabilities would be diminished if they were tempted to study for the examination (Li 1995, p. 206). For instance, the father of Yelü Puru, a Khitan prince who excelled in the civil service examination, was whipped two hundred times by the ruling class as a punishment lest the practice should effeminate their tribal tradition (Guo 1994, pp. 98-99, Li 1995, p. 206).

A similar situation occurred in the Jin Dynasty (1125-1234 A.D.) created by Jurden nomad occupying territories above Yangzi River. Jin emperors quickly embraced the Chinese governmental system and employed Chinese officials via keju in their regime. At the same time, they were sinitized by anti-physical Confucianism, leading to degradation of their warlike spirit. They grew to appreciate the advanced administrative system and became out-and-out Chinese, which partly resulted in their decline in physical prowess and sowed the seeds of their destruction (Xue 2004, p. 1-45). Subsequently, they fell victim to the ruthless Mongolians. On the other hand, the Han-ruled Song Dynasty (960-1279 A.D.) was particularly notorious for its civil-over-martial attitude. It had to conclude treaties with Khitan and Jurden, paying huge tributes regularly so as to secure peace. It was during this time that the proverb "good iron is not beaten into nails; good men are not made into soldiers" permeated society.

The Mongolians established the Yuan Dynasty (1279-1368 A.D.), but their leader Qubilai Khan refused to resurrect the keju system as some advisors requested in attempting to rule the country by Confucianism. Their disapproval was simple. When Mongolian cavalries approached the Southern Song capital Linan, not a single official echoed the call to defend the dynasty. The empress lamented, "My country treated Confucian scholars very well for three hundred years. The Emperor's heir and I have now run into serious difficulties, but officials have either resigned or deserted their posts to flee as cowards. How can you face those former emperors under the earth?" (Li 1995, p. 224). The Mongolians called the Confucianists feishi (useless scholars). The abolition of the keju corresponds to the low status of Confucianists under the Yuan Dynasty. "In the Great Yuan Decree, people are divided into ten ranks. The first are officials and the second are governmental employees (who cannot be officials). They are precious and helpful to the country; ...the seventh are artisans, the eighth are prostitutes, the ninth are the Confucianists, and the tenth are the beggars. They are despicable and useless to the country"3 (Li 1995, p. 236, Xiao 1999, p. 102). It can be argued that the Yuans' lasting less than 90 years is partly due to their abolition of the keju, through which the Han Chinese could have been co-opted into the regime. As a result, nepotism, cronyism, and corruption became rampant, as many people obtained governmental posts through the backdoor under the Mongolians.

The Manchu nomads destroyed the Ming Dynasty (1368-1644 A.D.) and created the Qing Dynasty (1644-1912 A.D.). They must have learnt a lesson from Mongolians, since they reinstated the keju system and enticed the disgruntled Chinese into administrative posts, distracting them from any thought of revolt. The Ming patriot Gu Yanwu pointed out that "as time went by, the longer the examination was carried out, the more ridiculous the contents became. The foreign race, the Manchus,

\footnotetext{
3 Tartars' (Mongolian) law: First is official, second governmental employee, third monk, fourth Daoist Priest, fifth doctor, sixth laborer, seventh hunter, eighth artisan, ninth Confucianist, tenth beggar. Though two sets of rankings are slightly different, Confucianist's status is still very low.
} 
intended to use this examination to constrain the thoughts of scholars who would indulge in academic study without any desire to resist foreign rule. Bagu (stereotyped writing) was a useful tool adopted by the Manchus to rule the country" (Cai 1992, p. 82). Therefore an identical process occurred. Although the Manchus were able to rule China for over 250 years, they gradually lost the warlike spirit of their forefathers through sinification. After a series of military defeats at the hands of Western powers, China was given the name 'Sick Man of East Asia' (dongya bingfu).

\title{
Social impact
}

Since people who passed the civil service examinations enjoyed a much higher social status in Chinese society, it was rational for many people to study Confucian Classics, whereas the percentage of martial artists became minuscule. Anything related to labor was despised by the public. 'One who excelled in academic study should hold a post in the civil administration' (xueer you zeshi) was the motto for Chinese people, to whom success in civil service examinations was the most important thing in their lives. The notion of 'civil over martial' (zhongwen qingwu) eventually reached its peak from the Song Dynasty onwards, due to the effects of the examination system, which for the first time encompassed all classes in the society, and dictated a family's wealth and prospects. Moreover, owing to the dreadful warlordism experienced by Song's emperor, they used the examinations to limit the development of alternative military and aristocratic power centers, and to draw into their government the intellectuals from newly emerging regions in Southern China. The purpose of these Song emperors was obvious. They did not want military generals to possess academic knowledge, and, at the same time, civil servants to have military connections (He 2006, pp. 228-252).

The collusion of wen and wu would produce talented military statesmen who would be detrimental to imperial security". The aftermath, the idea that 'everything is low-class work except academic study' (wanban jie xiapin wei you dushu gao), permeated the country. People who passed the martial service examination were often illiterate, while civil administrators had absolutely no idea of military matters ${ }^{5}$. Martial artists, who were only needed in wartime, were further denigrated by the public in peacetime for their embarrassing behavior. Since $w u$ people were physically muscular but culturally uneducated, those who could not pass martial service examinations usually rode roughshod over people and committed countless crimes, thus creating social problems that left a bad impression on Chinese people (Yang, Zhu, and Zhang 1992, p. 419).

It was this sedentary culture, reinforced by civil service examinations that forced people wanting success in getting official posts to cram up on Confucian Classics, however indigestible they were. Candidates for the exams were required to memorize a vast amount of classical material and were never required to demonstrate the ability either to theorize or challenge a particular premise. Scholars studied day and night, even year after year, preparing and taking exams. Ichisada Miyazaki (1981, p. 16) describes the core contents needed to pass the lowest exam:

\begin{abstract}
It was usual for a boy to enter school at the age of eight and to complete the general classical education at fifteen. The heart of the curriculum was the classics. If we count the number of characters in the classics that boys were required to learn by heart, we get the following figures: Analects 11,705, Mencius 34,685, Book of Changes 24,107, Book of Documents 25,700, Book of Poetry 39,234, Book of Rites 99,010, Zuo Zhuan 196,845. The total number of characters a student had to learn, then, was 431,286... The task of having to memorize textual material amounting to more than 400,000 characters is
\end{abstract}

\footnotetext{
${ }^{4}$ Yue Fei (1103-1142 A.D.), a talented military officer murdered by Emperor Song Gaozong, was a perfect example of the civil-over-martial attitude.

${ }^{5}$ Although martial service examinations required written tests on war classics, most candidates send agents to write exams for them in connivance with the examiners, who tolerated this practice.
} 
enough to make one reel. They required exactly six years of memorizing, at the rate of two hundred characters a day.

The asymmetrical balance of wen and $w u$ made physical exercise trivial compared to academic study. Classical learning, the foundation of generalists rather generals, was stressed, and any manifestations of strength and valor were correspondingly disparaged as being rough and uncouth. As a consequence, people were buried in classic books day and night, without any interest in physical exercise, let alone sport, a notion that did occur until westerners introduced it in the mid-nineteenth century. As soon as China ceded Taiwan to Japan in 1895, the occupiers were amazed that the Taiwanese had no folk dancing, which seemed to exist in every nation in the world. Nor did they have modern sports (Cai 1992, p. 88).

The Song Dynasty Emperor, Song Zhenzong (969-1022 A.D.), gave a vivid and acute account of his intentions and the social phenomenon of keju:

To enrich your family, there is no need to buy good land:

Books hold a thousand measures of grain.

For an easy life, there is no need to build a mansion:

In books are found houses of gold.

When you go out, do not be upset if no one follows you:

In books there will be a crowd of horses and carriages.

If you wish to marry, don't be upset if you don't have a go-between:

In books there are girls with faces like jade.

A young man who wishes to be somebody

will devote his time to the Classics.

He will face the window and read. (Liu and Li 2006, p. 163)

To many Chinese people, books contained "grain, gold, girls, and lots more" worth fighting for. Reading was seen as a jumping board to official ranks, which can be seen from Chinese proverbs: "After ten years' hard study by a cold window noticed by none, his fame fills the land once honors are won." No wonder Louie (2002, p. 19) said, "Participation or success in the imperial examinations was a respected part of the masculine image and signified a desirability and sexual power that has led to countless 'scholar-beauty' romance tales." The sedentary lifestyle of Confucian scholars was perfectly demonstrated by one Taiwanese principal, who stated that during the late Qing Dynasty "students have to walk genteelly to classrooms. If a student was seen by a teacher running to the classroom, the perpetrator's bottom will be spanked five times. Then he will be told that students are not allowed to run." This showed how despised the use of body was in the past (Zhao 1975, p. 351). Behavior that did not conform to Confucian standards was considered both barbaric and uncivilized.

Gernet (1982, p. 331) observed that "the lettered Chinese, apart from a few exceptions, was to be a pure intellectual who thought that games of skill and athletic competitions were things for the lower classes," and they preferred highbrow leisure activities, such as "learned literature, painting, calligraphy, the collection of books and works of art, and the designing of gardens". Since intellectuals were buried in books, those people were dubbed as 'pale-faced scholars' (paimian shusheng), meaning they hardly went out to exercise and were often physically weak. As a result, pre-modern Chinese scholars do nothing but study, get very little exercise, and have no idea of how to live a balanced life. In today's standards, especially from a Western perspective, they are pictured as effete intellectuals, "weaklings who can't truss a chicken," (shouwu fuji zhili) and "useless scholars" (wuyong shusheng).

\section{Conclusion}

This article has examined the colossal impact of Confucianism and the civil service examination on shaping the public's view of how men should behave, and the use of the body in pre-modern China. Confucianism evolved into an official ideology to serve imperialist interests. Inadvertently, it 
constructed an anti-physical culture, reinforced by civil service examinations. Downing (2008) argues that the eighteenth-century British prizefighter could be both polite and manly, a balance of masculine identity. But in the case of imperial China, the possession and memorization of Confucian classics were a source of power in achieving the wen type of masculinity, or the so-called 'soft masculinity'. This culminated in the successes at keju, and allowed no space for the $w u$ aspect of masculinity to develop. The political institution of Confucianism and the civil service examination clearly played a vital role in disciplining the body.

As Song (2004, p. 157) has rightly pointed out, "the male-male relationship played a more important role in the construction of masculinity than the male-female relationship did." As the argument goes on how the Chinese should behave, Confucian philosophy was an affair for elite men, who developed the ideas and established the perspectives of their understanding. The sedentary Confucian gentlemen became the guardians, promoters, and models of Confucianism for Chinese society. Their thoughts, not those of women and non-elite men, filled the pages of the texts, belonging to a masculine realm of political power and culture in ancient China. Even though novels such as The Romance of the Three Kingdoms and The Water Margin present wu images of characters that were extremely popular in Chinese society, the reality suggested otherwise. The civil service examination certainly had a significant influence on Chinese people. It inspired the people to study hard to attend the examination and achieve their pursuits. Even today, Chinese people still value education and examination and consider occupations requiring physical labor are for those who are more brawn than brain (Zeng 1999, Bo 2006).

It is interesting to note that this anti-physical culture extends to East Asian societies deeply influenced by Confucianism and civil service examination. Taiwan, in particular, preserved such bona fide Confucian thought and examination system that academic study has been overemphasized at the expense of physical education and sport (Yu 2007). Similarly, Chinese-dominated Singapore also displays a negative attitude towards physical culture despite British colonial rule (Horton 2001). The Koreans adopted the rigid examination system in the tenth century based on Confucianism that forced parents to push their children into success educationally (Yi 1993).

The wen-over-wu attitude even influenced the mindset of overseas Chinese. Steve Gewecke, baseball coach of Los Angeles Alhambra High School, whose Chinese students accounted for twothirds of the school, made an emotional plea to Chinese-Americans to participate in sports. The baseball team has fifty players, but only comprises seven Asian players, four of whom are Chinese. As Gewecke said, "Our school has 1,500 male students. Most players come from the group of five hundred people, but I only get four players from the other group of one thousand (Chinese) people." He carried on saying, "academic study is undoubtedly most important, but life is not only about study. Last year, one Chinese student came to a baseball tryout and was very impressive. But he only joined the team one day before being told by his parents to pull out in order to spend more time on SAT preparation" (Taiwan ribao, February 6, 2003) ${ }^{6}$. This phenomenon deserves further research in the future.

\section{REFERENCES}

Birdwhistell, J. D. (2007). Mencius and masculinities: Dynamics of power, morality and maternal thinking. Albany: State University of New York Press.

Bo, Y. [real name Y. Guo]. (2006). Xiaren de guocui jiaoyu /The quintessence of horrible education/. Shanxi: Beiyue wenyi chuban she.

Bresciani, U. (2001). Reinventing Confucianism: The New Confucian Movement. Taipei: Taipei Ricci Institute.

Cai, Z. (1993). Riju shidai taiwan bangqiu yundong fanzhan guocheng zhi yanjiu: Yi 1895 (Minzhi 28) nian zhi 1926 (Dazheng 15) nina wei zhongxin. Taipei: Taiwan Normal University, unpublished Masters dissertation.

\footnotetext{
${ }^{6}$ Taiwan ribao (Taiwan Daily) is Chinese version but only published in Los Angeles. I am indebted to the contributor Zhong Mengwen, who was the Boston Redsox's Pacific-Asian scout.
} 
Confucius (annotated by Xi Zhu and Boqian Jiang) (1960). Yuyi guangjie sishu duben: Lunyu /Annotating and interpreting the Four Books: Analects/. Taipei: Qiming.

Confucius (annotated and translated by B. Yang and D. Liu) (2009). Confucius: The Analects. Taipei: Lianjing.

Crossley, P. K. (1999). A Translucent Mirror: History and Identity in Qing Imperial Ideology. Berkeley: University of California Press.

Dikotter, F. (1992). The Discourse of Race in Modern China. Stanford, CA: Stanford University Press.

Downing, K. (2008) The gentleman boxer: Boxing, manners, and masculinity in eighteenth-century England. Men and Masculinities. Retreived from July 11, 2009, from http://jmm.sagepub.com /cgi/rapidpdf/1097184 X08318181v1.

Elias, N., Dunning, E. (1986). Quest for excitement: sport and leisure in the civilizing process. Oxford, UK: Blackwell.

Elman, B. A. (2000). A cultural history of civil examinations in late imperial China. Berkeley: University of California Press.

$\mathrm{Fu}, \mathrm{X}$. (1994). Tangdai keju yu wenxue /Civil service examination and literature in Tang dynasty/. Taipei: Wenshi chuban she.

Gernet, J. (translated by J. R. Foster) (1982). A History of Chinese Civilization. Cambridge, UK: Cambridge University Press.

Gu, Y. (1976). Rizhi lu /Daily accumulation of knowledge/. Vol. 19. Taipei: Minglun chuban she.

Guo, Q. (1994). Zhongguo gudai koushi zhidu /The examination system of ancient China/. Taipei: Taiwan shangwu.

He, Z. (2006). Keju yu songdai shehui /Civil service examination and Song dynasty/. Beijing: Shangwu yinshu guan.

Holt, R. (1989). Sport and the British: A Modern History. Oxford: Oxford University Press.

Horton, P. (2001). Complex Creolization: The evolution of modern sport in Singapore. Sport History Review, 3, 77-104.

Jin, G., Liu, Q. (1994). Xingsheng yu weiji: Lun zhongguo shehui chao wending jiegou /Prosperity and crisis: The super stable structure of Chinese society/. Taipei: Fengyun shidai chuban.

Jin, Y. (1991). Zhongguo xiandai hua yu zhishi fenzi /China's modernization and its intellectuals/. Taipei: Shibao wenhua.

Kang, Y. (1993). Lunyu shiyi /Interpretations of Analects/. Gaoxiong: Liwen.

Li, S. (1999). Zhongguo rujiao shi /The history of Chinese Confucianism/. Shanghai: Shanghai renmin chuban she.

Li, X. (1995). Zhongguo keju zhidu shi /The history of civil service examination in China/. Taipei: Wenjin chuban she.

Liu, H., Li, B. (2006). Zhongguo keju shi /The history of civil service examination in China/. $2^{\text {nd }}$ ed. Shanghai: Dongfang chuban zhongxin.

Liu, H. (1992). Zhongguo xuanshi zhidu shi /The selection system of officials in Chinal. Hunan: Hunan jiaoyu chuban she.

Liu, Z. (1977). Qingdai keju /Civil service examination in Qing dynasty/. Taipei: Dongda tushu.

Louie, K. (2002). Theorising Chinese masculinity: Society and gender in China. Cambridge: Cambridge University Press.

Mandarin Chinese Mini Dictionary. Retrieved July 5, 2009, from World Wide Web: http://140.111.1.43/cgibin/gdic/gsweb.cgi?o=ddictionary.

Mangan, J. A. (1998). The Games Ethic and Imperialism: Aspects of the Diffusion of an Ideal. $2^{\text {nd }}$ ed. London: Frank Cass.

Marshall, D. B. (2009). A canoe and a tent and God's great out-of-doors: Muscular Christianity and the flight from domesticity, 1890s-1930s. In H. Ellis and J. Meyer (Eds.), Masculinity and the other: Historical perspectives. Newcastle-upon-Tyne: Cambridge Scholars.

Mencius (annotated by Xi Zhu and Boqian Jiang) (1960). Yuyi guangjie sishu duben: Mengzi /Annotating and interpreting the Four Books: Mencius/. Taipei: Qiming.

Merson, J. (1990). The Genius That Was China: East and West in the Making of the Modern World. New York: Overlook Press.

Miyazaki, I. (1981). China's examination hell: The civil service examinations of Imperial China. Translated by Conrad Schirokauer. New Haven: Yale University Press. 
Money, T. (1997). Manly \& Muscular Diversions: Public Schools and the Nineteenth-Century Sporting Revival. London: Duckworth.

Putney, C. (2001). Muscular Christianity: Manhood and Sports in Protestant America, 1990-1920. Cambridge, Mass.: Harvard University Press.

Song, G. (2004). The fragile scholar: Power and masculinity in Chinese culture. Hong Kong: Hong Kong University Press.

Taiwan ribao /Taiwan Daily/.

Terrill, R. (2003). The new Chinese empire: And what it means for the United States. New York: Basic Books.

Tu, W. M. (1996). Confucian traditions in east Asian modernity: Moral education and economic culture in Japan and the four mini-dragons. Cambridge, Mass.: Harvard University Press.

Wang, R. (2007). Zhongguo keju koushi yu shehui yingxiang /Chinese civil service examination system and its impacts/. Changsha: Yuelu shushe.

Wang, Y. (2002). Keju zhidu yu shehui fengqi /Civil service examination and social atmosphere/. In Wang, Bingzhao and Yong Xu (Eds), Zhongguo keju zhidu yanjiu/The research of Chinese civil service examination/. Shijiazhuang: Hebei chuban she.

Xiao, Q. (1999). Yuanchao shi xinlun /New essays on history of Yuan dynasty/. Taipei: Yunchen wenhua.

Xue, R. (2004). Jindai keju /Civil service examination in Jin dynasty/. Beijing: Zhongguo shehui kexue chuban she.

Yang, X., Zhu, C., Zhang, H. (1992). Zhongguo koushi zhidu shi ziliao xuanbian /The selected papers on Chinese examination system/. Hefei: Huangshan shushe.

Yi, S. M. (translated by L. Han) (1993). Gaoli chaoxian liangchao de keju zhidu /The civil service examination system in Georyo and Chosun dynasties/. Beijing: Beijing daxue chuban she.

Yu, J. (2007). Playing in Isolation: A History of Baseball in Taiwan. Lincoln, NE: University of Nebraska Press. Zeng, K. (1999). Dragon gate: Competitive examinations and their consequences. London: Cassell.

Zhao, H. (1996). Liuchao shehui wenhua xintai /Social and cultural psychology during six dynasties/. Taipei: Wenjin.

Zhao, J. (1976). Lunyu xintan /New research on Analects/. Beijing: Renmin chuban she.

Zhao, Z. (1995). Mingdai xuexiao yu keju zhidu yanjiu /The research of school education and civil service examination in Ming dynasty/. Beijing: Yanshan chuban she.

Zhao, T. (1975). Changzhong xiyu yundong de huiyi /The memory of physical education and sport at Changrong high school/. Tainan: Changrong High School.

AUTHOR'S ADDRESS: Junwei Yu

National Taiwan College of Physical Education

Department of Physical Education

No. 16, Section 1, Shuang-Shih Road Taichung, Taiwan, 404

Email: chunweiyu@yahoo.com 